Saudi Journal of Oral and Dental Research

Abbreviated Key Title: Saudi J Oral Dent Res

ISSN 2518-1300 (Print) |ISSN 2518-1297 (Online)

Scholars Middle East Publishers, Dubai, United Arab Emirates

Journal homepage: https://saudijournals.com/sjodr

\title{
Study to Assess the Comprehensive Oral and Cardio-Metabolic Health and its Associated Risk Factors among Bus Drivers and Conductors in Lucknow
}

\author{
Abhishek Dubey ${ }^{1}$, Kapila Kumar ${ }^{2}$, Balendra Pratap Singh ${ }^{3 *}$, Suryakant ${ }^{4}$, Sunita Tiwari ${ }^{5}$, Veerendra Verma ${ }^{6}$ \\ ${ }^{1,2}$ Research Associate, Department of Prosthodontics, King George's Medical University, Lucknow, India \\ ${ }^{3}$ Professor, Department of Prosthodontics, King George's Medical University, Lucknow, India \\ ${ }^{4}$ Department of Respiratory Medicine, King George's Medical University, Lucknow, India \\ ${ }^{5}$ Department of Physiology, King George's Medical University, Lucknow, India \\ ${ }^{6}$ Professor, Department of Otorhinolaryngology, King George's Medical University, Lucknow, India
}

DOI: $10.36348 /$ sjodr.2020.v05i10.001

| Received: 19.09.2020 | Accepted: 27.09.2020 | Published: 05.10.2020

*Corresponding author: Abhishek Dubey

\section{Abstract}

Objectives: To assess oral health status and prevalence of obesity, hypertension and diabetes mellitus and sleep related disorders in bus conductors and drivers. Method: Cross-sectional survey was conducted at interstate bus terminal of Lucknow district. Total 156 bus conductors and drivers were enrolled in this study. Oral health status was assessed by WHO oral health questionnaire and prevalence of obesity, hypertension, diabetes and sleep related disorders were recorded using standardized questionnaire and biochemical investigations. Data was analysed using SPSS version 25.0 at significance level of 0.05. Result: The mean systolic and diastolic blood pressure was found 127.1 and 85.3 respectively for all the subjects. Mean value was observed $36.9 \mathrm{~cm}$ for neck circumference, a mean score of 3.1 was found for mallampati grading and a mean score of 5.9 was observed for Epworth sleepiness score for all the studied subjects. The mean value for Serum Cholesterol, triglyceride and HDL-C were found 174.7, 153.8 and $54.5 \mathrm{mg} / \mathrm{dl}$ respectively. Mean value of serum uric acid were found $5.4 \mathrm{mg} / \mathrm{dl}$ and Plasma glucose (fasting) was found 100.3mg/dl in the given subjects. Conclusion: As bus drivers and conductors belong to lower socio economic status, thus free health checkup camps should be organized so that they can seek medical aid. Awareness must be created and Psychological counseling must be provided so that they adopt a healthy lifestyle and learn to cope up with the stress. Implementation of strict laws and rules are also advised so that safety of drivers and public is maintained.

Keywords: Sleep, oral health, leukoplakia, blood pressure, accidents.

Copyright @ 2020: This is an open-access article distributed under the terms of the Creative Commons Attribution license which permits unrestricted use, distribution, and reproduction in any medium for non-commercial use (NonCommercial, or CC-BY-NC) provided the original author and source are credited.

\section{INTRODUCTION}

Obstructive sleep apnea (OSA) is posing serious detrimental effect on health of Indian population [1]. It may worsen further due to increase in obesity and other related cardiovascular co-morbidities i.e. type 2 diabetes mellitus (T2DM) and Hypertension. These conditions will create enormous socioeconomic burden to the country [2]. Moreover, it was observed that cardiovascular diseases could be caused by several risk factors like physical inactivity, lifestyle, unhealthy diet, substance abuse (especially tobacco and alcohol), hypertension (HTN), obesity, diabetes, and dyslipidemia [3].

Out of several occupations commercial drivers particularly bus or truck drivers are more prone to cardiovascular problems and sleep disorders. Lack of education, negligible medical facilities and low socio economic status make them more vulnerable [4].
Anthropometric parameters are predictive markers for the various obesity related phenotype including central obesity. Waist circumference and Hip circumference represents a high trend towards fat deposition [5]. Increasing neck circumference is an indicator of fat deposition in and around upper air way. This might cause narrowing of the upper airway resulting in increased chances of either decrease in air flow and or complete cessation of airway during sleep i.e. obstructive sleep apnea, a highest prevalent sleep breathing disorder. For the screening purposes of the fat deposition in and around upper air way, measurement of neck circumference and Mallampati Grading are widely used assessments worldwide. Epworth sleepiness score is a unique tool to assess degree of sleepiness [6]. 
In a systematic review it was concluded that drivers bear several risk factors which ultimately leads to compromised health conditions like cardiovascular disorders, diabetes etc. These risk factors comprises of unhealthy lifestyle and diet, lack of sleep and exercises, substance abuse, obesity, hypertension [7]. Due to less information available in this area the current study was planned to garner some more facts and particulars. Moreover, there are limited Indian studies which have focused on several risk factors in one study itself. Thus, the main objective of this study was to assess several risk factors, which were associated with the metabolic abnormalities including weight gain, obesity, hyperglycemia, elevated blood pressure and high occurrence of oral precancerous lesions and oral precancerous conditions.

\section{MATERIAL AND METHODS}

Sampling procedure was used for recruitment of subjects in community setting at Inter-state bus terminals of Lucknow. Anthropometric measurements (height, weight, BMI, and neck circumference), Vital measurements (Blood pressure, heart rate) were measured in community setting of Lucknow as per standard process. Overnight Polysomnography study was carried out in Sleep Laboratory existed in Department of Respiratory Medicine at King Georges Medical University, Lucknow. Standard approved methods were used for Biochemical analysis of blood samples for serum leptin, total cholesterol, HDL cholesterol, LDL cholesterol, VLDL, and triglycerides in Department of Biochemistry, King Georges Medical University, Lucknow. After taking written informed consent and approval from institutional ethics committee (9857/Ethics/R.Cell-16), total 156 Subjects were enrolled as per inclusion and exclusion criteria. Tools and techniques were standardized including Oral health status assessment tools, Cardio-metabolic assessment tools, Anthropometric Parameters, Body Mass Index (BMI in $\mathrm{Kg} / \mathrm{m} 2$ ), Waist Circumference $(\mathrm{cm})$, Neck Circumference $(\mathrm{cm})$, and Waist Hip Ratio. Vital Parameters, Blood Pressure and Heart rate, Biochemical Assay: Fasting blood plasma glucose level, Sleep assessment tools, Epworth Sleepiness Scale (ESS), Sleep Diary and Full night Polysomnography, Hindi version of Short form health survey (SF-36) was used for assessment of health related quality of life (QOL) and ENT evaluation for Mallamputti Scaling.

\section{RESULTS}

The Mean age of the subjects was 39.3 years. Most of the risk factors were associated with the duration of the service of the subject's type of profession, responsibilities, timings as well as nature of the job. This might affect the risk for metabolic abnormalities including weight gain, obesity, hyperglycemia, elevated blood pressure and high occurrence of oral precancerous lesions and oral precancerous conditions. The mean service duration was found 17 years in all subjects (Table 1).

Anthropometric parameters are predictive markers for the various obesity related phenotype including central obesity. Waist circumference and Hip circumference was measured in all subjects and mean values were observed as 91.1 and 93.6 respectively in all studied subjects.

These values represent a high trend towards fat deposition in the central region of the body which might again result in hyperglycemia and elevated blood pressure. The mean systolic and diastolic blood pressure was measured during the screening assessment of the subjects and found 127.1 and 85.3 respectively for all the subjects (Table 1).

Table-1: Demographic details of the Subjects (Mean \pm SD)

\begin{tabular}{|l|l|}
\hline Variable & Mean \pm SD \\
\hline Age (in years) & $39.3 \pm 12$ \\
\hline Service duration (in years) & $17 \pm 8.9$ \\
\hline Hight (in cm) & $165.8 \pm 6.1$ \\
\hline Weight (in kg) & $68.2 \pm 11.8$ \\
\hline Waist circumference (in cm) & $91.1 \pm 12.6$ \\
\hline Hip circumference (in cm) & $93.6 \pm 8.5$ \\
\hline Systolic BP (mm of Hg) & $127.1 \pm 18.5$ \\
\hline Diastolic BP (mm of Hg) & $85.3 \pm 10.6$ \\
\hline
\end{tabular}

In this study, various Sleep disorders related risk factors were also assessed to screen risk of the sleep disorders in the studied population. Neck circumference (in cm), Mallampati Grading, Epworth Sleepiness Score and STOP-BANG score were measured. Mean value was observed $36.9 \mathrm{~cm}$ for neck circumference in studied subjects. A mean score of 3.1 was found for mallampati grading during assessment of upper airway structure in the subjects. Epworth sleepiness score is a unique tool to assess degree of sleepiness in assessed subject. We found the mean score of 5.9 for all the studied subjects. STOP-BANG score is a subjective tool to screen risk of occurrence of sleep breathing disorder in the population. A high score indicates higher risk of occurrence of sleep breathing disorder in the population. We got a mean score value of 2.6 in the studied population (Table 2). 
Table-2: Sleep disorders related risk factors of the Subjects (Mean \pm SD)

\begin{tabular}{|l|l|}
\hline Variable & \% (n) \\
\hline Neck circumference $(\mathbf{\geq 4 0} \mathbf{~ c m})$ & $17.9(28)$ \\
\hline Mallampati Grading $(\geq \mathbf{3})$ & $70.5(110)$ \\
\hline Epworth Sleepiness Score $(\mathbf{\geq 6})$ & $51.2(80)$ \\
\hline Epworth Sleepiness Score $(\geq \mathbf{1 0})$ & $13.4(21)$ \\
\hline STOP-BANG score $(\mathbf{3})$ & $17.3(27)$ \\
\hline
\end{tabular}

Increasing neck circumference is an indicator of fat deposition in and around upper air way. This might cause narrowing of the upper airway resulting in increased chances of either decrease in air flow and or complete cessation of airway during sleep i.e. obstructive sleep apnea, a highest prevalent sleep breathing disorder. For the screening purposes of the fat deposition in and around upper air way, measurement of neck circumference and Mallampati Grading are widely used assessments worldwide. A measurement higher than $40 \mathrm{~cm}$ for neck circumference is used as a cut-off for the indication of increasing neck circumference in an individual, while Mallampati Grading was used to asses inner crowding of the oral cavity part of the upper airway.
Daytime sleepiness is an indicator of sleep breathing disorder. A high score represents higher incidence of chances of dosing and or sleep during daytime. Epworth Sleepiness Score (ESS) more than 6 shows excessive daytime sleepiness while ESS more than 10 show pathology related with sleep breathing disorder. (Table 3)

Neck circumference $\geq 40 \mathrm{~cm}$ was observed in $17.9 \%(\mathrm{n}=28)$ and Mallampati Grading $\geq 3$ was found in $70.5 \%(n=110)$ of the studied population. Epworth Sleepiness Score $\geq 6$ was found in $51.2 \%(n=80)$ while a pathological level of sleepiness (Epworth Sleepiness Score $\geq 10)$ was traced in $13.4 \%(n=21)$ of population. STOP-BANG score $\geq 3$ was found in $17.3 \%(n=27)$ of subjects. (Table 3)

Table-3: sleep disorders related risk factors of the Subjects (\% distribution)

\begin{tabular}{|c|c|}
\hline Variable & Mean \pm SD \\
\hline Neck circumference (in cm) & $36.9 \pm 2.8$ \\
\hline Mallampati Grading (1-4) & $3.1 \pm 0.8$ \\
\hline Epworth Sleepiness Score (0-24) & $5.9 \pm 3.5$ \\
\hline STOP-BANG score (0-8) & $2.6 \pm 1.5$ \\
\hline
\end{tabular}

Extreme occupational exposure of stress, unscheduled sleep, and tobacco chewing, smoking and alcohol intake might lead to high incidence of Candidiasis, Geographic tongue, Leukoplakia, OSMF (oral submucous fibrosis) and Erythroplakia in the subjects studied. We clinically examined all the subjects for the presence of Oral pre-cancer condition/lesions.
Candidiasis, Geographic tongue and lichen planus were observed in three (one in each) subjects. Leukoplakia and OSMF was found in 24 individuals (12 in each condition/lesion). A very serious premalignant oral lesion type, Erythroplakia, was seen in 4 subjects (Table 4).

Table-4: Pre-Oral cancer condition/lesions of the Subjects (\% distribution)

\begin{tabular}{|l|l|}
\hline Pre-Oral cancer condition/lesions & $\%(\mathbf{n})$ \\
\hline Candidiasis & $0.6(1)$ \\
\hline Geographic tongue & $0.6(1)$ \\
\hline Leukoplakia & $7.6(12)$ \\
\hline lichen planus & $0.6(1)$ \\
\hline OSMF & $7.6(12)$ \\
\hline Erythroplakia & $2.5(4)$ \\
\hline Total & $31(19.8)$ \\
\hline
\end{tabular}

Chronic alcoholism, smoking, tobacco use in any form are few well known risks factors for occurrence of Pre-Oral cancer condition/lesions in exposed subjects. In this study $1.9 \%(n=3)$ subjects claimed for being ex-smokers. Smoking, alcoholism and Tobacco chewing were observed in $40.3 \%(n=63)$,
$26.9 \%(42)$ and $69.2 \%(\mathrm{n}=108)$ subjects respectively. A total of $3.8 \%(n=6)$ and $1.9 \%(n=3)$ subjects claimed of being Ex-alcoholic and ex-tobacco users. Alcoholism, smoking and tobacco chewing simultaneously were present in $20.5 \% \quad(n=32)$ of the studied population (Figure 1). 


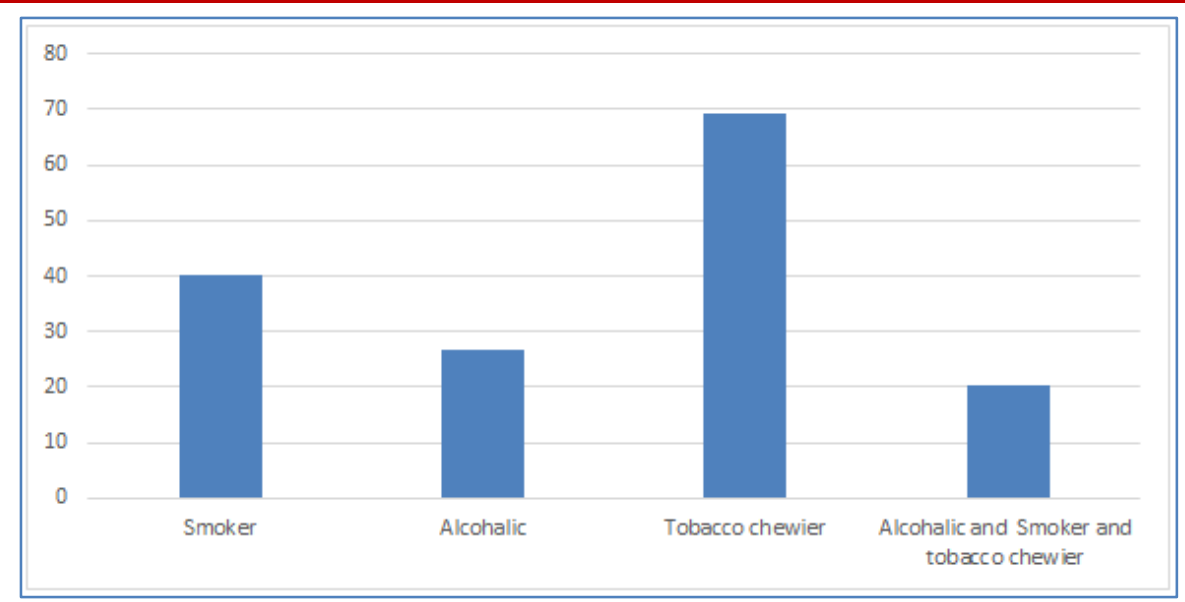

Fig-1: Pre-Oral cancer condition/lesions related risk factors in the Subjects (\% distribution)

Occupational work load hazards along with chronic alcoholism, smoking, tobacco use in any form are few well known significant health risk factors such as obesity, dyslipidemia, hyperglycemia and hypertension in the population. These conditions further pooled up with other physiological factors and increase the chances of adverse or fatal cardiovascular events in the subjects. Biochemical and clinical examinations were done to asses these conditions in the subjects the mean value for Serum Cholesterol, triglyceride and HDL-C were found 174.7, 153.8 and $54.5 \mathrm{mg} / \mathrm{dl}$ respectively. Mean value of serum uric acid were found $5.4 \mathrm{mg} / \mathrm{dl}$ in the studied population. Plasma glucose (fasting) was found $100.3 \mathrm{mg} / \mathrm{dl}$ in the given subjects. (figure 2)

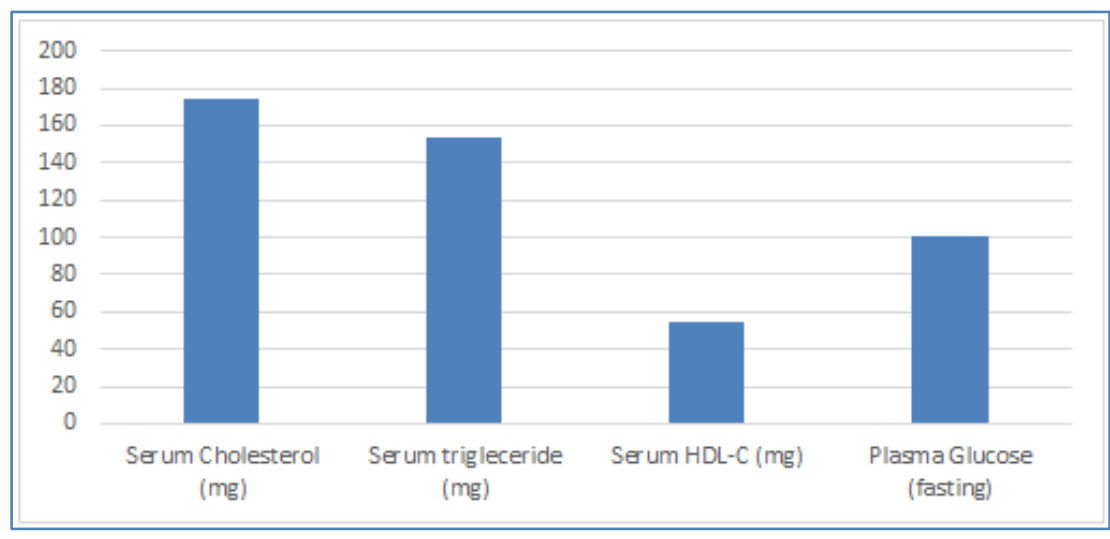

Fig-2: Biochemical Parameters of the of the Subjects (mean)

Borderline high Total Cholesterol (between 200 and $239 \mathrm{mg} / \mathrm{dL})$ was found in $22.4 \%(\mathrm{n}=35)$ of studied subjects. In $3.2 \% \quad(n=5)$ subjects, high total cholesterol (higher than $240 \mathrm{mg} / \mathrm{dL}$ ) was seen. Borderline high LDL cholesterol (130-159 mg) was found in $8.3 \%(n=13)$ of studied population. Low HDL (less than $40 \mathrm{mg} / \mathrm{dl})$ was found in $10.2 \%(\mathrm{n}=16)$ of subjects while borderline high triglycerides (150 to 199 $\mathrm{mg} / \mathrm{dL})$ was observed in $21.1 \%(\mathrm{n}=33)$ of individuals. Serum high triglycerides (200 to $499 \mathrm{mg} / \mathrm{dL}$ ) was observed in $17.9 \% \quad(n=28)$ subjects while very high triglycerides level was $(500 \mathrm{mg} / \mathrm{dL}$ and above) seen in one person. (Table 5)

Table-5: Abnormalities in Lipid Parameters of the of the Subjects

\begin{tabular}{|c|c|}
\hline Variable & $\%(\mathbf{n})$ \\
\hline Borderline high Total Cholesterol (between $200 \mathrm{and} 239 \mathrm{mg} / \mathrm{dL})$ & $22.4(35)$ \\
\hline High Total Cholesterol (higher than $240 \mathrm{mg} / \mathrm{dL})$ & $3.2(5)$ \\
\hline Borderline high LDL cholesterol $(130-159 \mathrm{mg})$ & $8.3(13)$ \\
\hline Low HDL (less than $40 \mathrm{mg} / \mathrm{dl})$ & $10.2(16)$ \\
\hline Borderline high triglycerides $(150 \mathrm{to} 199 \mathrm{mg} / \mathrm{dL})$ & $21.1(33)$ \\
\hline High triglycerides $(200$ to $499 \mathrm{mg} / \mathrm{dL})$ & $17.9(28)$ \\
\hline Very high triglycerides $(500 \mathrm{mg} / \mathrm{dL}$ and above) & $0.6(1)$ \\
\hline
\end{tabular}


Abnormalities in fasting Glucose levels of the Subjects were assessed and increased Glucose levels $(\geq 100-109 \mathrm{mg} / \mathrm{dl})$ were observed in $9.6 \% \quad(\mathrm{n}=15)$ subjects while Impaired Fasting Hyperglycemia
(IFG)110-126 mg/dl) and Type 2 Diabetes $(\geq 127$ $\mathrm{mg} / \mathrm{dl})$ were diagnosed in $7.7 \%(\mathrm{n}=12)$ and $12.1 \%$ $(\mathrm{n}=19)$ subjects respectively. (Table 6)

Table-6: Abnormalities in fasting Glucose levels of the Subject

\begin{tabular}{|c|c|}
\hline Variable & \% (n) \\
\hline Increased Glucose Level $(\geq 100-109 \mathrm{mg} / \mathrm{dl})$ & $9.6 \%(15)$ \\
\hline Impaired Fasting Hyperglycemia (IFG)110-126 mg/dl) & 7 (12) \\
\hline Type 2 Diabetes $(\geq 127 \mathrm{mg} / \mathrm{dl})$ & $12.1 \%(19)$ \\
\hline
\end{tabular}

Elevated Blood Pressure (SBP 120-129 mm $\mathrm{Hg})$ was found in $3.8 \%(\mathrm{n}=6)$ subjects. High Blood Pressure Stage 1 (SBP 130-139 mm Hg) was observed in $19.2 \%(n=30)$ subjects while Stage 1 High Blood Pressure (DBP $80-89 \mathrm{~mm} \mathrm{Hg}$ ) was found in $19.8 \%$ $(\mathrm{n}=31)$ subjects. Stage 2 High Blood Pressure (SBP $\geq$ 140 to $179 \mathrm{~mm} \mathrm{Hg})$ was found in $15.3 \%(\mathrm{n}=24)$ studied subjects while Stage 2 High Blood Pressure (DBP 90 to $119 \mathrm{~mm} \mathrm{Hg}$ ) was found in $34.6 \%$ (54) subjects. A state of Hypertensive Crisis (SBP $\geq 180$ or higher) was seen in two individuals while Hypertensive Crisis (DBP 120 $\mathrm{mm} \mathrm{Hg}$ or Higher) was diagnosed in one person. (Table 7)

Table-7: Abnormalities in Blood Pressure levels of the Subjects

\begin{tabular}{|c|c|}
\hline Variable & \% (n) \\
\hline Elevated Blood Pressure SBP 120-129 mm Hg & $3.8(6)$ \\
\hline High Blood Pressure Stage 1 SBP 130-139 mm Hg & $19.2(30)$ \\
\hline High Blood Pressure Stage 1 DBP 80-89 mm Hg & $19.8(31)$ \\
\hline High Blood Pressure Stage 2 SBP $\geq 140$ to $179 \mathrm{~mm} \mathrm{Hg}$ & $15.3(24)$ \\
\hline High Blood Pressure Stage 2 DBP 90 to $119 \mathrm{~mm} \mathrm{Hg}$ & $34.6(54)$ \\
\hline HYPERTENSIVE CRISIS SBP $\geq 180$ or higher & $1.2(2)$ \\
\hline HYPERTENSIVE CRISISDBP 120 mm Hg or Higher & $0.6(1)$ \\
\hline
\end{tabular}

\section{DISCUSSION}

In this study the mean age recorded was 39 years which somewhere corresponds to the study by Erhiano et al. [8], which stated that age might be a reason of cardio metabolic problems. Since bus drivers are prone to cardiovascular diseases due to work stress hence possibility of hypertension is much higher among them. Moreover, waist hip ratio (WHR) is considered to be predictive marker for cardiovascular diseases than BMI or waist circumference [9]. In our study Waist circumference and Hip circumference was measured in all subjects and means values were observed as 91.1 and 93.6 respectively in all studied subjects. These values represent a high trend towards fat deposition in the central region of the body which might again result in hyperglycemia and elevated blood pressure. Our study also corresponds to the study by Pushpa and Kanchan where they observed elevated waist-hip ratio and BP in drivers as compared to non-drivers as controls [10]. Our study also corresponds to the study done by Udayar et al. which stated an elevated WHR among transport drivers [11].

Studies have also found that blood pressure (BP) could also rise due to immense exposure of air and noise pollution, especially among bus drivers, which could result in cardio metabolic problems. In an adult Normal blood pressure (BP) is considered to be a systolic BP (SBP) of $120 \mathrm{mmHg}$ and a diastolic BP (DBP) of $80 \mathrm{mmHg}[12,13]$. In this study the mean systolic and diastolic blood pressure was found 127.1 and $85.3 \mathrm{~mm} \mathrm{Hg}$ respectively for all the subjects, which was marginal. Elevated Blood Pressure (SBP 120-129 $\mathrm{mm} \mathrm{Hg}$ ) was found in $3.8 \%(\mathrm{n}=6)$ subjects. High Blood Pressure Stage 1 (SBP 130-139 mm Hg) was observed in $19.2 \% \quad(n=30)$ subjects while Stage 1 High Blood Pressure (DBP $80-89 \mathrm{~mm} \mathrm{Hg}$ ) was found in $19.8 \%$ $(\mathrm{n}=31)$ subjects. Stage 2 High Blood Pressure (SBP $\geq$ 140 to $179 \mathrm{~mm} \mathrm{Hg}$ ) was found in $15.3 \%(\mathrm{n}=24)$ studied subjects while Stage 2 High Blood Pressure (DBP 90 to $119 \mathrm{~mm} \mathrm{Hg}$ ) was found in $34.6 \%$ (54) subjects. A state of hypertensive crisis with $\mathrm{SBP} \geq 180$ or higher was seen in two individuals while with DBP $120 \mathrm{~mm} \mathrm{Hg}$ or Higher was diagnosed in one person. Our results are comparable with the study by Pushpa and Kanchana[10]. This could be due to several factors which includes, air and noise pollution, physical inactivity, sedentary lifestyle and stress. Hypertension is the silent killer and an increase in the level of BP could result in stroke, which is the second most frequent cause of mortality [14].

When glucose levels and cholesterol levels were evaluated an elevated level were observed which signifies the presence of metabolic syndrome. It also corresponds to the study by Showande and Odukoya, in which hyper triglyceridemia along with central obesity was observed. The study also focused on the fact that among obese drivers hyper lipidemia occurrence might result into diabetes mellitus [4]. 
Chronic alcoholism, smoking, tobacco use in any form are few well known risks factors for occurrence of Pre-Oral cancer condition/lesions in exposed subjects. In this study $1.9 \%(n=3)$ subjects claimed for being ex-smokers. Smoking, alcoholism and Tobacco chewing were observed in $40.3 \%(n=63)$, $26.9 \%(42)$ and $69.2 \%(n=108)$ subjects respectively. A total of $3.8 \%(n=6)$ and $1.9 \%(n=3)$ subjects claimed of being Ex-alcoholic and ex-tobacco users. Alcoholism, smoking and tobacco chewing simultaneously were present in $20.5 \%(n=32)$ of the studied population. This also corresponds to some earlier findings where alcohol consumption was done by 40 to $50 \%$ of the bus drivers [15-17]. Alcohol consumption is another risk factor for the development of hypertension as drinking might result into road accidents [4]. Smoking is another risk factor and studies have related it to hypertension, which very much corresponds to our study $[15,18]$. In a recent meta-analysis and systematic review it was concluded that hypertension is a burden among bus drivers globally [3].

In this study we endeavor to assess sleeping disorders which could be another factor for health related problems among drivers. Our study is also in accordance with several studies related to sleep disorders or sleepiness among drivers, which results in falling asleep at the wheel and becomes the major reason of accidents. Although there are several factors which includes sleep deprivation, obstructive sleep apnea or workshifts [19-23].

In this study occurrence of oral pre cancer condition or lesion was also assessed. Studies have reflected that due to long working hours, stress, sleep disorders drivers often indulge themselves in habit of substance abuse, which ultimately results in oral health issues. Our study is in accordance with several studies where prevalence of oral precancer was seen among the drivers [24-26].

\section{ACKNOWLEDGEMENTS}

The author are grateful to UPCST (Uttar Pradesh Council of Science and Technology, Lucknow, UP, India) for providing us the financial support (CST/D 20/7/16 \& CST/RPD/D 14-09-17).

\section{CONCLUSION}

This study gives a comprehensive outlook on the compromised health condition of bus drivers and conductors which arises due to extensive driving (long hours and irregular shifts). The risk factors associated gives us the clear picture of prevalence of sleep disorders, substance abuse and cardio metabolic problems. As bus drivers and conductors belong to lower socio economic status, thus free health checkup camps should be organized so that they can seek medical aid without any hassle. Awareness must be created among them so that they adopt a healthy lifestyle and should be aware of pros and cons of risk factors. Psychological counseling is also advised so that they learn to cope up with the occupational and personal stress. Implementation of strict laws and rules are also advised so that safety of drivers and public is maintained.

\section{REFERENCES}

1. Panda, S., Taly, A. B., Sinha, S., Gururaj, G., Girish, N., \& Nagaraja, D. (2012). Sleep-related disorders among a healthy population in South India. Neurology India, 60(1), 68.

2. Jehan, S., Myers, A. K., Zizi, F., Pandi-Perumal, S. R., Jean-Louis, G., \& McFarlane, S. I. (2018). Obesity, obstructive sleep apnea and type 2 diabetes mellitus: Epidemiology and pathophysiologic insights. Sleep medicine and disorders: international journal, 2(3), 52.

3. Krishnamoorthy, Y., Sarveswaran, G., \& Sakthivel, M. (2020). Prevalence of hypertension among professional drivers: Evidence from 2000 to 2017-A systematic review and metaanalysis. Journal of Postgraduate Medicine, 66(2), 81.

4. Showande, S., \& Odukoya, I. (2020). Prevalence and clusters of modifiable cardiovascular disease risk factors among intra-city commercial motor vehicle drivers in a Nigerian metropolitan city. Ghana Medical Journal, 54(2), 100-109.

5. Neeland, I. J., Ayers, C. R., Rohatgi, A. K., Turer, A. T., Berry, J. D., Das, S. R., ... \& de Lemos, J. A. (2013). Associations of visceral and abdominal subcutaneous adipose tissue with markers of cardiac and metabolic risk in obese adults. Obesity, 21(9), E439-E447.

6. Patil, S. P., Schneider, H., Schwartz, A. R., \& Smith, P. L. (2007). Adult obstructive sleep apnea: pathophysiology and diagnosis. Chest, 132(1), 325337.

7. Crizzle, A. M., Bigelow, P., Adams, D., Gooderham, S., Myers, A. M., \& Thiffault, P. (2017). Health and wellness of long-haul truck and bus drivers: A systematic literature review and directions for future research. Journal of Transport \& Health, 7, 90-109.

8. Erhiano, E. E., Igbokwe, V. U., El-Khashab, M. M., Okolo, R. U., \& Awosan, K. J. (2015). Prevalence of hypertension among commercial bus drivers in Sokoto, Sokoto State Nigeria. Int J Med Med Sci, 2(3), 34-39.

9. Joshi, A. R., \& Vaidya, S. M. (2017). Evaluation of perceived stress in bus drivers of Pune city. National Journal of Physiology, Pharmacy and Pharmacology, 7(1), 90.

10. Pushpa, K., \& Kanchana, R. (2019). Comparison of waist-hip ratio, prehypertension, and hypertension in young male bus drivers and non-drivers of Bengaluru city. National Journal of Physiology, Pharmacy and Pharmacology, 9(1), 90-94. 
11. Udayar, S. E., Konduru, R. K., Kumar, P. K. B., Shivachandiran, V., \& Srinivas, T. (2015). Study of cardiovascular risk factors among transport drivers in rural area of andhra pradesh. National Journal of Community Medicine, 6(4), 566-569.

12. Dzhambov, A. M., \& Dimitrova, D. D. (2018). Residential road traffic noise as a risk factor for hypertension in adults: Systematic review and meta-analysis of analytic studies published in the period 2011-2017. Environmental Pollution, 240, 306-318.

13. Khosravipour, M., Khosravi, F., Ashtarian, H., Rezaei, M., Moradi, Z., \& Mohammadi Sarableh, H. (2020). The effects of exposure to different noise frequency patterns on blood pressure components and hypertension. International archives of occupational and environmental health.

14. Jameson, J. L., Kasper, D. L., Longo, D. L., Fauci, A. S., Hauser, S. L., \& Loscalzo, J. (2018). Harrison's principles of internal medicine.

15. Das, M., Mallick, A., \& Biswas, S. (2019). Prevalence of hypertension and its concomitants: An exploratory study among a group of bus drivers in Kolkata, West Bengal. Antrocom: Online Journal of Anthropology, 15(2).

16. Tobin, E. A., Ofili, A. N., Asogun, D. A., Igbinosun, P. O., Igba, K. O., \& Idahosa, A. V. (2013). Prevalence of hypertension and associated factors among inter-city drivers in an urban city in South-South Nigeria. International Journal of Research in Medicine, 2(3), 5-12.

17. Udayar, S. E., Sampath, S., \& ArunD, S. S. (2015). Epidemiological study of cardiovascular risk factors among public transport drivers in rural area of Chittoor district of Andhra Pradesh. Int $J$ Community Med Public Health, 2(4), 415-420.

18. Niskanen, L., Laaksonen, D. E., Nyyssönen, K., Punnonen, K., Valkonen, V. P., Fuentes, R., ... \& Salonen, J. T. (2004). Inflammation, abdominal obesity, and smoking as predictors of hypertension. Hypertension, 44(6), 859-865.
19. Chen, G. X., Fang, Y., Guo, F., \& Hanowski, R. J. (2016). The influence of daily sleep patterns of commercial truck drivers on driving performance. Accident analysis \& prevention, 91, 55-63.

20. Chiu, H. Y., Chen, P. Y., Chuang, L. P., Chen, N. H., Tu, Y. K., Hsieh, Y. J., ... \& Guilleminault, C. (2017). Diagnostic accuracy of the Berlin questionnaire, STOP-BANG, STOP, and Epworth sleepiness scale in detecting obstructive sleep apnea: a bivariate meta-analysis. Sleep medicine reviews, 36, 57-70.

21. Krishnaswamy, U. M., Chhabria, M. S., \& Rao, A. (2016). Excessive sleepiness, sleep hygiene, and coping strategies among night bus drivers: A crosssectional study. Indian journal of occupational and environmental medicine, 20(2), 84.

22. Shriane, A. E., Ferguson, S. A., Jay, S. M., \& Vincent, G. E. (2020). Sleep hygiene in shift workers: A systematic literature review. Sleep Medicine Reviews, 101336.

23. Vennelle, M., Engleman, H. M., \& Douglas, N. J. (2010). Sleepiness and sleep-related accidents in commercial bus drivers. Sleep and breathing, 14(1), 39-42.

24. Di Cesare, T., D’Alatri, L., \& Marchese, M. R. (2020). The prevalence of signs and symptoms of laryngopharyngeal reflux and laryngeal precancerous lesions in urban taxi drivers. European Archives of Oto-RhinoLaryngology, 1-7.

25. Singhal, A., Agrawal, P., \& Agrawal, V. K. (2018). Prevalence and determinants of tobacco use and oral sub mucous fibrosis in auto-rickshaw drivers at Bareilly, Uttar Pradesh, India. International Surgery Journal, 5(4), 1449-1453.

26. Shetty, P., Khargekar, N. C., Debnath, A., Khargekar, N. R., Srivastava, B. K., \& Hakeen, N. E. F. (2017). Determinants of tobacco use and prevalence of oral precancerous lesions in cab drivers in Bengaluru City, India. International journal of preventive medicine, 8 . 